NBER WORKING PAPER SERIES

\title{
ABILITY AND EMPLOYER LEARNING: EVIDENCE FROM THE ECONOMIST LABOR MARKET
}

\author{
Paul Oyer \\ Working Paper 12989 \\ http://www.nber.org/papers/w12989 \\ NATIONAL BUREAU OF ECONOMIC RESEARCH \\ 1050 Massachusetts Avenue \\ Cambridge, MA 02138 \\ March 2007
}

I am grateful to the placement directors and graduate program administrators that provided historical economics job market materials. Thanks also to Liran Einav, Robert Gibbons, Michael Grubb, Takeo Hoshi, Daiji Kawaguchi, Walter Oi, Hideo Owan, Scott Schaefer, an anonymous referee, and participants in the 2006 SOLE Meetings, the NBER Summer Institute, and the 2006 TRIO Conference at Hitotsubashi University for useful comments and conversations. James Caputo, Eric Forister, Michael Grubb, Diane Lee, and Khine Williams provided excellent research assistance. The views expressed herein are those of the author(s) and do not necessarily reflect the views of the National Bureau of Economic Research.

(C) 2007 by Paul Oyer. All rights reserved. Short sections of text, not to exceed two paragraphs, may be quoted without explicit permission provided that full credit, including $\odot$ notice, is given to the source. 
Ability and Employer Learning: Evidence from the Economist Labor Market

Paul Oyer

NBER Working Paper No. 12989

March 2007

JEL No. J24,J44,M51

\begin{abstract}
$\underline{\text { ABSTRACT }}$
I study the human capital development and firm-worker matching processes for $\mathrm{PhD}$ economists. This group is useful for this purpose because the types of jobs they hold can be easily categorized and they have an observable productivity measure (that is, publications.) I derive a two-period model to motivate an empirical analysis of economist job matching upon graduation, matching ten years later, and productivity in the first ten years. I show that matching to a higher ranked institution affects productivity. I present evidence that employers improve their estimates of economists' ability early in their career in a way that determines longer-term job placement. I also find that the initial placement of economists to institutions does not show much evidence of systematic misallocation along observable characteristics.
\end{abstract}

\author{
Paul Oyer \\ Graduate School of Business \\ Stanford University \\ 518 Memorial Way \\ Stanford, CA 94305-5015 \\ and NBER \\ pauloyer@stanford.edu
}




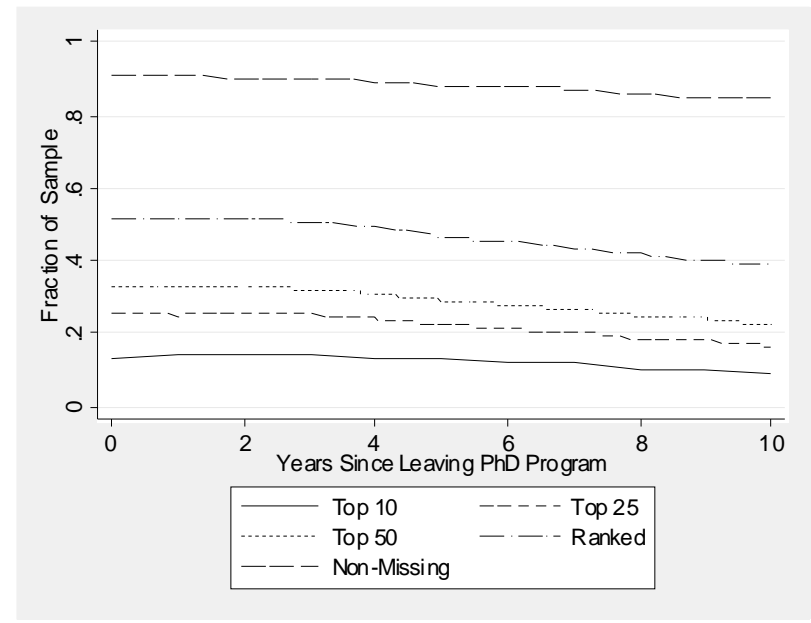

Figure 1: Economist Job Sector Mobility. Institution ratings based on "econphd.net". "Ranked" includes tenure track jobs at ranked universities and all jobs at ranked non-universities. "Non-Missing" includes anyone whose position is known.

\section{Introduction}

Matching the right workers to the right firms presents one of the largest opportunities to create surplus in employment relationships and in the economy more generally. For decades, labor economists have studied the theory of job market matching (see, for example, Jovanovic (1979)) and its empirical ramifications (see Farber (1999) for a discussion of many relevant studies.) But, while a select group of economists studies the job matching process, all economists engage in the job matching process at various points. This begins with the rite of passage of "going on the market" in the fall of the last year in graduate school and continues as economists consider, or actually make, job changes throughout their careers. In this paper, I use the economist labor market to study the economics of labor markets. I focus on how economists are matched to employers when they enter the labor market and after ten years of experience. I consider the implications for the job matching process and human capital development.

Figures 1 and 2 establish some facts about economist mobility and motivate the analysis. In both figures (and throughout the paper), I use institutional rankings from econphd.net to divide economist jobs into six sectors - tenure track jobs at Top 10 universities, at Top 25 universities, at Top 50 universities, at other ranked institutions, any known job, and, finally, missing information. Figure 1 shows how the sample that I use is divided among these sectors over the first ten years after economists leave graduate school. The figure makes it clear that, on average, economists 


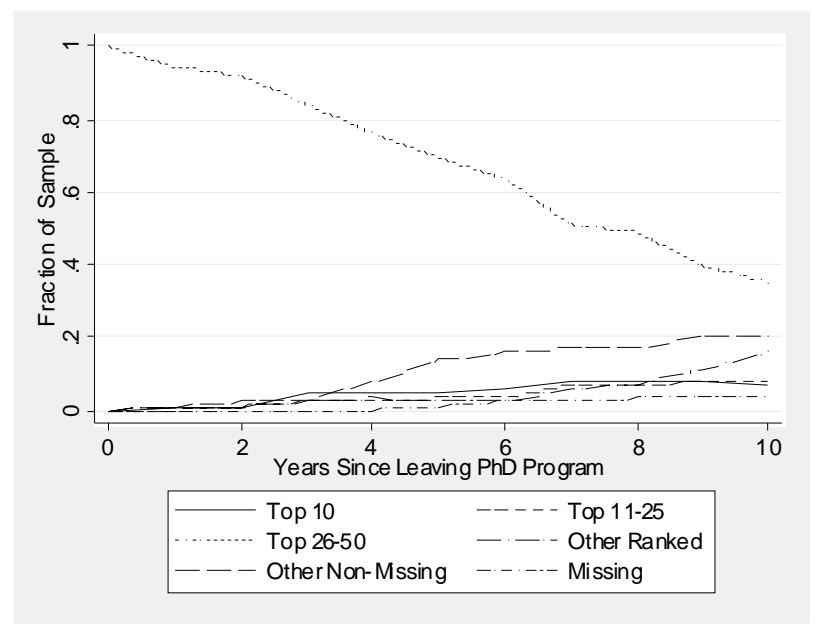

Figure 2: Sector Mobility Conditional on Initial Placement at Top26-50 School. Sample limited to economists whose first placement is a tenure-track job at a school that ranks between 26 and 50, according to econphd.net.

move to less prestigious institutions over the first decade of their careers. For example, $23.3 \%$ of the sample initially works in a tenure-track position at a Top 25 university. But, after ten years, only $16.6 \%$ of the sample works at a Top 25 school. The graph shows that this tendency to move "down" is consistent across all of these sectors.

While the average person moves down, a large fraction stay in the same sector or move up during these years. This can be seen in Figure 2, which focuses on economists that start their careers at universities ranked between \#26 and \#50 by econphd.net. After ten years, $35 \%$ of these economists are still at schools in this category and $15 \%$ have moved up to Top 25 schools while approximately half have either moved to an institution that is ranked below the Top 50 schools, to an unranked institution or business, or somewhere that I was not able to find them.

What drives these movements over the first ten years? I begin by deriving a stylized twoperiod model of careers where economists and employers match twice based on expectations about economists' research productivity. Expected productivity is a function of innate ability and human capital developed in school and on-the-job. In the model, higher-ranked employers want to employ the highest ability economists and help these economists generate more human capital. The three key endogenous variables in the model are job placement upon graduation, "second-period" job placement (which I define as job held ten years after leaving school), and "first-period" (that is, first ten years) research productivity.

Using a dataset of the careers of economics PhDs from seven graduate schools, I analyze these 
three outcomes and address four issues. First, I analyze the degree to which initial job sector affects early career productivity. I show that economists that work at higher ranked institutions are more productive than other economists, both because of selection and on-the-job human capital development. Second, I investigate how updated expectations about economists' ability during the first career period affects second period placement. That is, I analyze the employer learning process. The empirical results suggest that employers use productivity, and possibly unobserved factors that are correlated with productivity, to match economists with appropriate positions. Third, I show that the tendency to move "down" suggested by Figure 1 is a significant and consistent pattern in economist careers. I do not attempt to explain this pattern, leaving it as an avenue for potentially fruitful research into optimal organizational design. Finally, I ask whether employers of economists systematically make "mistakes" when hiring new economists by looking for correlations between observable characteristics and movement among sectors early in economist careers. Though I uncover no gross systematic errors, I do find suggestive evidence that individual employers could hire economists of higher average ability if they hired counter-cyclically.

These results should be of interest to economists and employers of economists for obvious reasons. But I hope they make a contribution to the literature on job matching and employer learning in the general economy. As is common in the Industrial Organization literature, focusing on a single market segment has some substantial advantages. First of all, the institutional details of this market are well understood in the economics community, potentially making it easier to impose certain assumptions in the theoretical and empirical analyses. Second, economist jobs are relatively easily observed and categorized. Third, research productivity provides a publicly observable performance measure. Though I focus on economists, many of these same features are found in other high skill professions where general human capital is important and individual's accomplishments are relatively easily observed. ${ }^{1}$

This paper adds to a long line of papers that model employees as having a person-specific ability parameter that is a sufficient statistic for productivity. In these models, it takes some time for employers to figure out a person's ability. Therefore, at any given moment, pay may not reflect ability. Farber and Gibbons (1996) investigate this issue and show that, as early careers develop, dynamic patterns in pay suggest that employers are learning individuals' ability (that is, they are inferring things that are unobservable when the person enters the labor market.) Altonji and Pierret (2001) provide further evidence on the importance of employer learning by showing that,

\footnotetext{
${ }^{1}$ For example, see Oyer (2006b) for an analysis of another group of high-skill workers - Stanford MBAs. In that paper, I use a panel dataset of jobs held and wages, but I have no performance information. I show that people who go into investment banking quickly develop specific human capital. This leads to long-term attachment to the industry and large income differentials.
} 
as a person's career develops and employers observe better signals of "ability", the coefficients on initially observable variables (such as education) decline in wage regressions and the coefficients on things learned over time (such as results of standardized tests) go up. They argue that this provides evidence of statistical discrimination in initial wages. Gibbons, Katz, Lemieux and Parent (2005) also look at learning, skill development, and sector mobility early in workers' careers. They look at wages and sector assignment. They find that high-wage sectors attract high-skill workers and give them relatively large opportunities for skill development.

I build a model that is similar, in many ways, to these prior studies. However, I focus on a smaller and more homogeneous labor market. Also, Farber and Gibbons (1996), Altonji and Pierret (2001), and Gibbons et al. (2005) look at how pay develops over time and generally assume that pay reflects productivity. Relative to these studies, I have the disadvantage of not having pay data and the advantage of access to a direct measure of productivity (specifically, research output.) I draw inferences about employee learning and human capital development based on the types of jobs people hold and their productivity..

This paper also adds to a long literature on the labor market for economists and is most closely related to two papers in that literature. Oyer (2006a) shows that getting a "good" initial position after finishing an economics $\mathrm{PhD}$ program leads an economist to be more likely to hold a "good" job later and to be more productive in terms of research. In the current paper, I analyze other factors that predict success along these same dimensions. I also explicitly model and analyze the value of employers' learning the ability of economists, as well as how efficiently employers select economists. Smeets, Warzynski and Coupe (2006) analyze how initial and later placement of economists vary with the reputation of the graduate program attended. They find that top graduates from second-tier economics departments are initially employed at better jobs than secondtier graduates from top departments. However, they find that the top department graduates end up producing more research and in better long-term positions. They speculate that this indicates some form of inefficiency in the initial allocation of economists or that schools put a lot of resources into marketing their best students. Using a very different dataset and different measures of success, I do not find a similar bias towards hiring top students at second tier schools. I discuss possible reasons for this apparent difference in results in Section $4.4 .^{2}$

\footnotetext{
${ }^{2}$ Using a very different approach, Chen and McKinnish (2005) argue that economics departments search for new faculty optimally in terms of breadth of fields. They develop a model where breadth of search for new economists is positively correlated with the quality of the searching department. This correlation stems from top departments' high standards demanding they search broadly in order to insure a large enough pool of qualified applicants and the fact that, because high quality departments quickly dispose of many applications, they incur a relatively low cost from searching broadly. They find evidence consistent with this model, using listings in Job Openings for Economists.
} 


\section{A Model of The Economist Labor Market}

In this section, I derive a stylized model of the economist labor market that will motivate the empirical work to follow. The model makes several assumptions that appear to be consistent with this market.

Assumption 1: Institutions that employ economists can be ordered (or at least categorized) with respect to how attractive it is to work there. ${ }^{3}$

Assumption 2: Economists vary in their research "ability" where ability is a combination of innate talent and human capital developed in school and on-the-job.

Assumption 3: It is efficient to match high-ability economists to more attractive positions. That is, like Gibbons et al. (2005) and many others, I will simply analyze efficient matching rather than modeling the firm's underlying optimization problem. I will take it as given that high-ranked institutions will make offers to the high ability economists and that, on average, an economist will want to work for the highest ranked institution that she can. ${ }^{4}$ In future work, I hope to use this data to draw inferences about optimal organizational design.

Assumpution 4: Economists and institutions engage in an initial match upon graduation. They then re-match based on updated information at the beginning of a second (and final) period. This assumption essentially takes a typical U.S. university tenure system as given. I leave explaining why such a system exists to others (see, for example, Carmichael (1988) and Kahn and Huberman (1988)).

With these assumptions in mind, consider economist $i$, entering the labor market (so she is entering career period $y=1$ ) in year $t$. Her ability is $\alpha_{i y}$ (or $\left.\alpha_{i 1}\right)$. Let $E_{t}\left(\alpha_{i y} \mid x_{i y t} ; z_{i y t}\right)$ be the market's (that is, the typical hiring institution) estimate of her ability as of $t$. $x$ is a vector of characteristics that are observable to the market and the econometrician, such as scholarships received, what graduate program she attended, and nationality. $z_{i y t}$ (or, more specifically in this context, $\left.z_{i 1 t}\right)$ is information that is observed by the market when she is looking for a job but not observed by the econometrician. This includes information in letters of reference, as well as assessments made during interviews and job talks. Define $\varepsilon_{i 1}=\alpha_{i 1}-E_{t}\left(\alpha_{i 1} \mid x_{i 1 t} ; z_{i 1 t}\right)$. Assuming the market's expectations of new economists are rational, the distribution of $\varepsilon_{i 1}$ will have mean zero. Let $\sigma_{\varepsilon 1}^{2}$ be the variance of $\varepsilon_{i 1} .^{5}$

\footnotetext{
${ }^{3}$ I will allow for individual variance in preference. However, I will assume, for example, that most people would prefer to work at a research university relative to a teaching-oriented college.

${ }^{4}$ Models that would justify this assumption include Miller (1984) and MacDonald (1982), as well as others where ability differences lead to comparative advantage across types of jobs.

${ }^{5}$ Note that if the distribution of $\varepsilon$ differs among economists, then employers may well have an incentive to trade
} 
If $E_{t}\left(\alpha_{i 1} \mid x_{i 1 t} ; z_{i 1 t}\right)>m_{1 t}$ (that is, if the market's assessment of her ability is above some cutoff), she goes to sector $16^{6}$ If not, then she goes to sector $0 .{ }^{7}$ As shown in Oyer (2006a), the ability cut-off depends on labor market conditions in the year the person seeks her initial position. That is, if labor market conditions are more favorable in year $g$ than in year $h, m_{1 h}>m_{1 g}$.

During period 1, two things may change the market's assessment of her ability - her ability may change as she gains human capital and the market may get a more informed signal of her innate ability. Assume that $\alpha_{i y}$ is determined by a combination of innate talent $\left(\alpha_{i}\right)$ and human capital developed on the job. Any human capital gained before entering the labor market (that is, in school) is fixed for this analysis, so I can define $\alpha_{i 1}=\alpha_{i}$. I model human capital acquisition during career period 1 as $\alpha_{i 2}=\alpha_{i}+\Sigma_{j=0}^{1} \beta_{j} s_{j 1}$ where $s_{j 1}=1$ if she spends career period 1 in sector $j$. In other words, second period ability is either $\alpha_{i}+\beta_{0}$ or $\alpha_{i}+\beta_{1}$, depending on which sector she works in during the first period.

Let $p_{i 2}$ be the person's publication record at the beginning of the second period. Assume that publication history is an additive combination of ability and random factors such that $p_{i 2}=\alpha_{i 2}+\delta_{i}$. Assume $\delta$ comes from a distribution with mean zero and variance $\sigma_{\delta}^{2}$. That is, I am assuming that the type of job the person gets in the first period affects her human capital and, therefore, her publication record as of the start of the second period. It will prove useful to rewrite $p_{i 2}=\alpha_{i 2}+\delta_{i}$ as $p_{i 2}=\alpha_{i}+\Sigma_{j=0}^{1} \beta_{j} s_{j 1}+\delta_{i}$.

Now consider economist $i$, entering the second period of her career $(y=2)$ in year $t$. Now $E_{t}\left(\alpha_{i 2} \mid x_{i 2 t}, p_{i 2}, s_{i 1} ; z_{i 2 t}\right)$ is the market's updated estimate of her ability as of $t$. Note that the market now conditions its expectations on her period 1 sector and publications. Given these expectations, she engages in a second match with the market. Specifically, she works in sector 1 in period 2 if $E_{t}\left(\alpha_{i 2} \mid x_{i 2 t}, p_{i 2}, s_{i 1} ; z_{i 2 t}\right)>m_{2 t}$. The market's (or the econometrician's) estimate of her ability may still be imperfect, so define $\varepsilon_{i 2}=\alpha_{i 2}-E_{t}\left(\alpha_{i 2} \mid x_{i 2 t}, p_{i 2}, s_{i 1} ; z_{i 2 t}\right)$ and $\sigma_{\varepsilon 2}^{2}$ to be the variance of $\varepsilon_{i 2}$.

This model of the economist labor market suggests a system of equations with three endogenous variables - sectors in the two periods and publication productivity in period 1. More specifically, one can think of the careers of economists as being characterized by the following three equations:

$$
s_{i 1}=I\left[E_{t}\left(\alpha_{i 1} \mid x_{i 1 t} ; z_{i 1 t}\right)>m_{1 t}\right]
$$

off expectations about $\alpha$ and $\varepsilon$. That is, it may pay to hire "risky" workers (as in Lazear (1998)), especially given the ease with which negative realizations on ability can be discarded through the tenure process. I briefly discuss how this could be empirically relevant to the analysis below in Section 4.4.

${ }^{6}$ The first and second subscripts on $m$ are for career period and year, respectively. This allows the employers to use different ability cutoffs at different stages of economists' careers and for the cutoff to vary with demand conditions.

${ }^{7}$ In the empirical analyses, I will allow for more than two sectors. 


$$
\begin{gathered}
p_{i 2}=\alpha_{i}+\Sigma_{j=1}^{2} \beta_{j} s_{j 1}+\delta_{i} \\
s_{i 2}=I\left[E_{t}\left(\alpha_{i 2} \mid x_{i 2 t}, p_{i 2}, s_{i 1} ; z_{i 2 t}\right)>m_{2 t}\right]
\end{gathered}
$$

where $I[$.$] is the indicator function. Using this theoretical framework, I will use data on economists$ to address four questions.

First, is there evidence that on-the-job human capital development does, in fact, affect productivity? This would imply that $\beta_{1}>\beta_{0}$.

Second, I look for evidence that employers of economists use first-period productivity $\left(p_{i 2}\right)$ to infer ability $\left(\alpha_{i}\right)$. This would suggest that $\sigma_{\varepsilon 2}^{2}$ will be smaller than $\sigma_{\varepsilon 1}^{2}$ and that equation (3) will be estimated more precisely than (1).

Third, I look for systematic evidence that, on average, economists move "down" over the course of their careers. This would show up empirically if $m_{2 t}>m_{1 t}$. At this point, I will make no attempt to isolate the exact reasons underlying this feature of the economist market.

Finally, I look for evidence to suggest possible systematic bias when hiring new economists by seeing if $\operatorname{corr}\left(x_{i 1 t}, \varepsilon_{i 1}\right) \neq 0$ for some $x$ characteristics.

\section{Empirical Framework}

\subsection{Data}

Before getting into the details of how I will attempt to estimate the model sketched in the last section, I describe the available data. I generated a panel dataset of the careers of graduates of seven economics PhD programs - the University of California at Berkeley, the University of Chicago, the University of Minnesota, MIT, Northwestern University, Stanford University, and the University of Texas. I got information on individuals at the time they entered the labor market from the books of CVs that each of these departments compiles and distributes every fall. I have the books for each fall from 1979 through 2003 for two of the seven schools. The initial books in the other five schools' series are from 1980, 1983, 1984, 1985, and 1987. I then used various sources to track all the people in the CV books year-by-year through 2004. I also matched economists with their publications using the online version of "EconLit." 8

The three endogenous variables highlighted in the model above are "sector" of first job after

\footnotetext{
${ }^{8}$ For further details on construction of the career and publications datasets, see Oyer (2006a).
} 
graduation, sector at some date later in economists' careers, and publication record at this same later date. ${ }^{9}$ Picking the starting point for period 2 requires some thought. On the one hand, the later I wait, the more the processes of learning and human capital development (not to mention long publication lags) will have unfolded. On the other hand, every year that I wait to start period 2 requires throwing away a cohort of recent graduates that have not yet had careers of the appropriate length. I ended up settling on ten years because this allows most people to go through the tenure review process and, when necessary, the resulting second job search. ${ }^{10}$ Therefore, throughout the analysis, career period 1 starts in the fall after the person is last listed in her school's CV book and period 2 begins in the fall ten years after the beginning of career period 1.

Rather than just the two sectors suggested in the model, I break the institutions that employ economists into six sectors. Using the rankings of universities provided by econphd.net, I define a person to be in the top sector $(s=5)$ if she holds a tenure-track job at a school ranked in the top 10. Sector 4 includes tenure-track jobs at schools ranked 11-25 and sector 3 is tenure-track jobs at other schools in the top 50. Sector 2 includes tenure-track jobs at all other schools ranked by econphd.net and jobs at all non-academic institutions ranked by econphd.net. Sector 1 includes any other person-year where I was able to identify the person's job. Finally, sector 0 is all person-years where I was not able to find the person. ${ }^{11}$ Summarizing

- $s=5$ if Top 10 job

- $s=4$ if other Top 25 job

- $s=3$ if other Top 50 job

- $s=2$ if other ranked job

- $s=1$ for all other non-missing jobs

- $s=0$ if missing.

\footnotetext{
${ }^{9}$ Given that I have annual data on publications and jobs, I could look at sector or publications year-by-year rather than just twice. However, as will become clear, it is difficult enough to get enough exogenous variation when looking at two dates. Adding more periods to the model would make the empirical work intractable.

${ }^{10}$ Many tenure reviews take place after six years. But that does not seem sufficient for my purposes because there are many examples of people who still hold tenure-track jobs at highly ranked institutions six years after graduation, despite having few or no publications. There are almost no such people after ten years.

${ }^{11}$ This predominantly consists of people who I never found and of person-years after some point where the person is last found through EconLit, the AEA directories, or internet search. There are also a few cases where a person is missing for a period in the middle of her career. If I first find the person one or more years after she left school, I assume the job she held when I found her was the one she held since graduation. The results are not sensitive to treating these observations as missing.
} 
Defining productivity also requires exercising some judgment. I could simply use the number of papers a person has published, but EconLit covers over 1,000 journals of widely varying impact. Also, the distribution of publication counts is highly skewed. Lots of economists have zero publications at the start of career period 2 and most have three or fewer. However, more than ten percent have more than ten published papers and some have many more. While taking the logs of number of publications might smooth out the long-right tail, the fact that over a third of the sample has zero publications presents a problem.

I use three different measures of $p_{i 2}$, each of which has different strengths and weaknesses. First, I define "publication category" such that

- $p_{i 2}=0$ if the person has no published papers at the start of career period 2

- $p_{i 2}=1$ if the person has one or two published papers at the start of career period 2

- $p_{i 2}=2$ if the person has three to five published papers at the start of career period 2

- $p_{i 2}=3$ if the person has six to ten published papers at the start of career period 2

- $p_{i 2}=4$ if the person has eleven to twenty published papers at the start of career period 2

- $p_{i 2}=5$ if the person has more than twenty published papers at the start of career period $2 .{ }^{12}$

The second measure of $p_{i 2}$ is an indicator variable that equals one if the person has published at least one paper in a "Top 5" journal (the American Economic Review, Econometrica, the Journal of Political Economy, the Quarterly Journal of Economics, and the Review of Economic Studies) at the start of period 2.

The third measure of $p_{i 2}$ is based on the "impact" of the journals where papers are published. I created a total impact measure by adding together the Journal Citation Reports impact factors of each journal where the person published a paper (adding the impact factor for the journal as many times as the person published in that particular journal. $)^{13}$ I used the impact factors provided on Tom Coupe's economist ranking web page (http://student.ulb.ac.be/ ${ }^{\sim}$ tcoupe/ranking.html) as of March 21, 2006. Because these correspond to a single year's measure of impact, there is quite a bit of noise in this measure. Given that $37 \%$ of the sample had zero publications ten years after leaving school, and another $7 \%$ had none in journals with positive impact factors, I could not take

\footnotetext{
${ }^{12}$ For details on the distribution of publications after ten years and the choice of the cutoffs in defining "publication category", see Oyer (2006a).

${ }^{13}$ To be very clear, if a person published two articles in a journal with an impact factor of 1 , one in a journal with an impact factor of 0.5 , and one in a journal with an impact factor of 0.25 , I assigned her a total impact of 2.75 .
} 
$\operatorname{logs}$ of this highly-skewed measure. Therefore, the third definition of $p_{i 2}$ is the person's percentile in the total impact measure distribution. For the approximately $44 \%$ with total impact of zero, I set $p_{i 2}=0.2206$.

The observable characteristics (that is, $x$ ) include several measures that should affect the market's perception of the person's ability as she leaves graduate school. The reputations of the individual schools vary considerably, so indicator variables for which program the person attended will be correlated with ability. From the CV, I was able to record whether the person received a National Science Foundation (NSF) graduate fellowship, whether the person was honorable mention for an NSF fellowship, and whether she was awarded a Sloan Foundation dissertation fellowship. NSF fellowships are awarded when the person enters graduate school or one year later. Sloan fellowships, which were discontinued in the late 1990's, were given for the last year of graduate study.

Summary statistics are displayed in Table 1 for economists in the fall after they leave school and the fall ten years later. The first column shows all available observations while the second column shows new graduates that can also be measured ten years later. The balanced sample in the final two columns includes 1,149 economists that last appeared in a CV book in the Fall of 1993 or earlier. The mix of schools across the balanced sample and the column (1) sample is different because schools vary in the first year their CV books are available.

The sample is predominantly male. While most economists in both samples went to US undergraduate schools, foreign students have become more common over time. NSF and Sloan fellowships are given to a relatively small group. NSF grants are highly concentrated at one graduate school in the sample. Sloan grants are more evenly spread among the schools, though the same school that accounts for more than $80 \%$ of the NSF grants in the sample also accounts for more than $40 \%$ of the Sloan grants.

In the estimates that follow, I will typically show the fixed effects for the school that ranks highest ("School A") and the one that ranks lowest ("School B") by any measure of job outcomes or publication productivity. The excluded category in these analyses is the school that ranks fourth out of seven by most measures, so these fixed effects can be thought of as measures of whether the top and bottom schools vary from the average. School A has the largest share of the sample because it has slightly bigger classes, on average, than other schools and because its CV books are available all the way back to 1979. The School B sample starts in the fall of 1983 and has noticeably smaller graduating classes than most of the other schools.

Approximately $33 \%$ of the sample starts their career in a tenure-track job at a top 50 university. However, after ten years, this fraction has dropped to $22 \%$. After ten years, the average number 


\begin{tabular}{|c|c|c|c|}
\hline & All & First Job & $\begin{array}{c}10 \text { Years } \\
\text { After Graduation }\end{array}$ \\
\hline Female & $21.2 \%$ & $19.6 \%$ & $19.6 \%$ \\
\hline US undergrad & $59.0 \%$ & $67.5 \%$ & $67.5 \%$ \\
\hline NSF Graduate Fellowship & $11.1 \%$ & $13.8 \%$ & $13.8 \%$ \\
\hline Sloan Dissertation Fellowship & $8.3 \%$ & $11.3 \%$ & $11.3 \%$ \\
\hline Grad School A & $22.8 \%$ & $27.2 \%$ & $27.2 \%$ \\
\hline Grad School B & $6.9 \%$ & $6.2 \%$ & $6.2 \%$ \\
\hline \multicolumn{4}{|l|}{$\%$ by Sector: } \\
\hline Top $10(s=5)$ & $12.6 \%$ & $13.2 \%$ & $9.5 \%$ \\
\hline Other Top $25(s=4)$ & $10.7 \%$ & $12.0 \%$ & $7.1 \%$ \\
\hline Other Top $50(s=3)$ & $7.1 \%$ & $7.7 \%$ & $5.6 \%$ \\
\hline Other Ranked & $35.4 \%$ & $34.4 \%$ & $32.8 \%$ \\
\hline Non-Missing & $24.1 \%$ & $24.1 \%$ & $29.4 \%$ \\
\hline Missing & $10.1 \%$ & $8.6 \%$ & $15.6 \%$ \\
\hline \multicolumn{4}{|l|}{ Papers: } \\
\hline Average Number & 0.129 & 0.131 & 4.453 \\
\hline Top 5 Journal Indicator & $1.1 \%$ & $1.4 \%$ & $25.2 \%$ \\
\hline Observations & 2,324 & 1,149 & 1,149 \\
\hline
\end{tabular}

Table 1: Summary Statistics. The sample is limited to people who appear in two or fewer CV books. The first two columns are means of each variable as of the Fall after the person last appears in a CV book. "All" includes all people from books sent out in 1979-2003. "Balanced Sample" includes those in books sent out in the Fall of 1993 or before so that it matches the sample of people ten years after leaving school. The final column includes this same sample ten years later. Grad Schools A \& B are the highest and lowest ranked programs in terms of average success of initial placement over the available time frame. "Top 10" and other ratings are based on econphd.net rankings of institutions and only include people with tenure-track jobs. "Ranked" indicates a tenure-track position at a university ranked by econphd.net or a position at a non-university ranked by econphd.net. Average number of papers includes all journal articles in EconLit and "Top 5 Journal Indicator" equals one if the person has published in one of the Top 5 economics journals (see text for list.) 
of publications is about four-and-a-half, the median is two, and about a quarter of the sample has published a paper in a Top 5 journal. There are nine economists with twenty-five or more publications after ten years.

\subsection{Empirical Specification and Identification}

Given the discrete nature of the sector measure, as well as two of the three productivity measures, I would ideally like to estimate ordered logit or ordered probit versions of equations (1)-(3). This presents no problems in the case of the initial placement equation because there are no endogenous variables on the right-hand side of the equation. Therefore, the first empirical equation updates equation (1) to be

$$
s_{i 1}=\left\{\begin{array}{ccc}
=5 & \text { if } & a+b x_{i 1 t}+\eta_{i 1 t} \geq m_{5 t 1} \\
=4 & \text { if } & m_{5 t 1}>a+b x_{i 1 t}+\eta_{i 1 t} \geq m_{4 t 1} \\
=3 & \text { if } & m_{4 t 1}>a+b x_{i 1 t}+\eta_{i 1 t} \geq m_{3 t 1} \\
=2 & \text { if } & m_{3 t 1}>a+b x_{i 1 t}+\eta_{i 1 t} \geq m_{2 t 1} \\
=1 & \text { if } & m_{2 t 1}>a+b x_{i 1 t}+\eta_{i 1 t} \geq m_{1 t 1} \\
=0 & \text { if } & m_{1 t 1}>a+b x_{i 1 t}+\eta_{i 1 t} .
\end{array}\right.
$$

Note that the sector cutoffs $(m)$ now have three subscripts. The first is for the sector, the second for the calendar year when the person starts career period 1, and the third is the career period.

Equation (2) cannot be estimated as written above because I do not observe $\alpha_{i}$. Therefore, I will estimate productivity empirically through the specification

$$
p_{i 2}=c+d x_{i 1 t}+\sum_{j=0}^{5} \beta_{j} I\left(s_{i 1}=j\right)+\delta_{i} .
$$

This includes any proxies for ability known when the person enters the job market (that is, $x_{i 1 t}$ ). The coefficients on the sector indicator variables (that is, the $\beta$ 's) capture the effect of human capital developed in the first period on productivity. However, this presents a challenge because first-period placement cannot be thought of as exogenous. Unobserved factors will affect both $s_{i 1}$ and $p_{i 2}$, so I need an instrument for $s_{i 1}$ to properly estimate (5). As in Oyer (2006a), I use the number of academic job listings in Job Openings for Economists (JOE) or a set of indicator variables for year of market entry as instruments. In using the JOE variable as an instrument, I am assuming it affects initial placement because it reflects demand for economists but that macro conditions at graduation only affect productivity through their effect on initial placement. The graduation year indicators have the advantage relative to the $J O E$ variable that they make fewer 
parametric assumptions about how demand varies from year-to-year for new economists. However, using class indicators as instruments requires the assumption that variations in average ability among graduating cohorts do not explain the variation in placement success for the group as a whole. This requires that demand be determined independent of economist ability which could happen if, for example, schools are assigned "slots" and they fill them independent of the average quality of new economists.

Finally, the second period sector can now be written

$$
s_{i 2}=\left\{\begin{array}{ccc}
=5 & \text { if } & e+f x_{i 2 t}+g p_{i 2}+\Sigma_{j=0}^{5} h_{j} I\left(s_{i 1}=j\right)+\eta_{i 2 t} \geq m_{5 t 2} \\
=4 & \text { if } & m_{5 t 2}>e+f x_{i 2 t}+g p_{i 2}+\Sigma_{j=0}^{5} h_{j} I\left(s_{i 1}=j\right)+\eta_{i 2 t} \geq m_{4 t 2} \\
=3 & \text { if } & m_{4 t 2}>e+f x_{i 2 t}+g p_{i 2}+\Sigma_{j=0}^{5} h_{j} I\left(s_{i 1}=j\right)+\eta_{i 2 t} \geq m_{3 t 2} \\
=2 & \text { if } & m_{3 t 2}>e+f x_{i 2 t}+g p_{i 2}+\Sigma_{j=0}^{5} h_{j} I\left(s_{i 1}=j\right)+\eta_{i 2 t} \geq m_{2 t 2} \\
=1 & \text { if } & m_{2 t 2}>e+f x_{i 2 t}+g p_{i 2}+\Sigma_{j=0}^{5} h_{j} I\left(s_{i 1}=j\right)+\eta_{i 2 t} \geq m_{1 t 2} \\
=0 & \text { if } & m_{1 t 2}>e+f x_{i 2 t}+g p_{i 2}+\Sigma_{j=0}^{5} h_{j} I\left(s_{i 1}=j\right)+\eta_{i 2 t} .
\end{array}\right.
$$

It is more difficult to solve the endogeneity problem for this equation, given that there are two endogenous explanatory variables. Given a few more instruments, I could estimate all three equations simultaneously using three-stage least squares or a GMM estimator. But I cannot justify excluding enough variables to identify all three equations. Alternatively, I could impose more structure and assumptions on the system of equations, but I do not have a realistic model in mind that would identify all the parameters. Therefore, at this stage I will settle for estimating various versions of the reduced form of the second period sector equation. I will then compare the coefficients and goodness-of-fit with the first period sector to draw tentative conclusions about the learning process.

\section{Results}

\subsection{Initial Placement}

I now use a series of ordered logits to estimate equation (4). The dependent variable is higher at institutions that rank the highest, so positive coefficients are associated with better ranking. The sample in the first two columns is all available initial placements, which includes people who started jobs in a summer or fall between 1980 and 2004. Columns (3) and (4) limits the sample to the "balanced sample" from the second column of Table 1, which will be the sample when estimating equation (6) below.

First, note that there is no relationship between first placement and the two demographic 
characteristics (gender and country of undergraduate institution.) This is consistent with (though not proof of) graduate schools not discriminating along either of these dimensions, or at least not discriminating differently than hiring institutions. If, for example, there were substantial gender discrimination in admissions (or affirmative action in favor of women), I would expect the women at a given school to be better (worse) job market candidates than the men and the female coefficient would be positive (negative) in the initial placement analyses.

Not surprisingly, the highest ranked school does significantly better with initial placements than the middle school and the lowest ranked does worse. Column (1) shows that NSF fellowships are also associated with better initial placements, even controlling for graduate institution. Note, however, that much of this relationship goes away when Sloan fellowships are added to the specification in Column (2). The Sloan coefficient is much larger than the NSF coefficient, though both are roughly equally likely in the raw data. This is the first evidence consistent with learning playing a role in economist placement. NSF fellowships are awarded near the beginning of graduate school when information about an economist's potential is relatively noisy. After the professors at a graduate school get a better signal of students' ability, they are asked to nominate candidates for Sloan fellowships. This is more closely related to the market's estimate of economists' ability shortly thereafter when they go on the job market.

The results for the balanced sample, in columns (3) and (4), are almost identical to those for the whole sample, though the standard errors are somewhat higher due to the smaller sample size. The one difference of any note is that the coefficient on US undergraduates is higher in the balanced sample. However, it is only significantly different from zero at the $15-17 \%$ level. Taking the coefficients literally, it would suggest that, before 1994, US undergraduates got more prestigious appointments than foreign students. Such a result could be caused by preferences for foreigners to return to their home countries (which would hurt their placement record because foreign US institutions tend to rank highly and because it would increase the chance I would not find them

so that they would be assigned $s_{i 1}=0$ ), immigration costs, or even a bigger advantage for English speakers in face-to-face interviews relative to written graduate student applications. However, given that the result is not even statistically significant, it is not worth trying to distinguish among these explanations.

\subsection{Productivity}

I now try to estimate equation (5). That is, I look at how research productivity during the first ten years of an economists' career (period 1) is affected by individual characteristics and human capital. Table 3 displays the results of seven specifications of the productivity equation (that is, 


\begin{tabular}{lccccc}
\hline \hline & \multicolumn{2}{c}{ All Years } & & \multicolumn{2}{c}{ Before 1994 } \\
& $(1)$ & $(2)$ & & $(3)$ & $(4)$ \\
\cline { 1 - 2 } \cline { 5 - 6 } Female & -0.0086 & -0.0139 & & 0.0823 & 0.0672 \\
& $(0.0923)$ & $(0.0923)$ & & $(0.1356)$ & $(0.1360)$ \\
U.S. undergrad & 0.0395 & 0.0527 & & 0.1719 & 0.1785 \\
& $(0.0837)$ & $(0.0839)$ & & $(0.1236)$ & $(0.1239)$ \\
Grad School A & 0.7006 & 0.7045 & & 0.6853 & 0.6554 \\
& $(0.1306)$ & $(0.1309)$ & & $(0.1829)$ & $(0.1833)$ \\
Grad School B & -1.429 & -1.389 & & -1.313 & -1.294 \\
& $(0.1704)$ & $(0.1711)$ & & $(0.2515)$ & $(0.2526)$ \\
NSF & 0.2335 & 0.1516 & & 0.3103 & 0.1860 \\
& $(0.0705)$ & $(0.0711)$ & & $(0.0947)$ & $(0.0962)$ \\
Sloan & & 1.518 & & 1.390 \\
& & $(0.1469)$ & & $(0.1871)$ \\
Observations & 2,324 & 2,324 & & 1,149 & 1,149 \\
Pseudo $R^{2}$ & 0.0339 & 0.0481 & 0.0358 & 0.0505 \\
\hline
\end{tabular}

Table 2: Initial Placement. An observation is a person. Each column shows the coefficients from an ordered logit where the dependent variable is five if the person holds a tenure-track job at a top-10 university (based on "econphd.net" rankings) in the Fall after she last appears in her school's book of CVs, four if she holds one at a top-25 (but not top-10) university, three if she holds one at a top-50 (but not top-25) university, two if she holds a tenure-track job at a university that is ranked (but not in the top-50) by econphd.net or a non-university that is ranked by econphd.net, one if she holds any other known job, and zero if she could not be found. The sample is limited to people who appear in two or fewer CV books. In columns (3) and (4), the sample is further limited so that it only includes people who were last in a CV book in 1993 or earlier so that the same sample can be used to analyze jobs ten years after leaving school. All the displayed explanatory variables are indicator variables. "Grad School A" is an indicator for graduating from the highest ranked of the seven graduate institutions. "Grad School B" is an indicatory for graduating from the lowest ranked institution. Each regression also has a full set of indicator variables for year on job market and graduate institutions. Standard errors are in parentheses. 
analyses where $p_{i 2}$ is the dependent variable.) In columns (1)-(3), the dependent variable is the "publication category" variable defined in Section 3.1. Column (1) reports the results of an ordered logit, which would be the natural way to analyze this categorical dependent variable. However, I will instrument for initial job rank in some specifications and it is more practical to do this in a least squares regression. For comparison purposes, column (2) reports an OLS regression with the same explanatory variables as the Column (1) ordered logit. Column (3) reports the results of a two-stage least squares regression where I instrument for initial job rank using the number of academic job openings in $J O E$ the year the person last went on the job market. The rest of the table shows the results of OLS and IV regressions that are similar to those in columns (2) and (3) but use the other measures of $p_{i 2} \cdot{ }^{14}$

First note that all the regressions that do not include initial job rank as an explanatory variable show relationships one might expect between various characteristics and research productivity. Women produce less, which is likely due to the fact that the first ten years after getting a $\mathrm{PhD}$ are a period with a high probability of having children. This probably leads many women to take some time off from research. Those who went to US undergraduate institutions also are more productive, which may reflect the lower cost of writing in English.

As one might expect given the initial placement results, School A graduates are relatively productive and School B graduates publish substantially less than other PhDs. Again, NSF and Sloan fellowships, which are likely to be correlated with expected ability, predict greater research output. As with initial placement, the fellowship that is awarded later in graduate school (Sloan) is a more informative predictor. These relationships largely hold up in the IV regressions that control for initial placement.

The IV results in columns (3), (5), and (7) all have coefficients that are consistent with economists building more research-oriented human capital if they work at more prestigious research institutions. The coefficients in columns (3) and (7) are significant at the $10 \%$ and $7 \%$ levels, respectively. The job rank coefficient that can be most easily interpreted is the 0.09 in column (7). This implies that moving up from a top 25 job to a top 10 job (or from a ranked job outside the top 50 to a Top 50 job or any other move up one job rank) leads to an increase of $9 \%$ in where the person stands in the cumulative distribution of impact for people with ten years of experience. In other words, suppose an economist would get an initial job at a school ranked 75th under certain macro conditions when she graduates and that she would have been in the 60th percentile of the impact distribution if she started her career at that institution. But now suppose the same economist

\footnotetext{
${ }^{14}$ Though some of the variables are different, the IV regressions are similar to those in Oyer (2006a).
} 


\begin{tabular}{|c|c|c|c|c|c|c|c|}
\hline \multirow[t]{2}{*}{ Dependent Variable } & \multicolumn{3}{|c|}{ Publication Category } & \multicolumn{2}{|c|}{ Top 5} & \multicolumn{2}{|c|}{ Impact } \\
\hline & $(1)$ & $(2)$ & $(3)$ & (4) & $(5)$ & $(6)$ & $(7)$ \\
\hline Female & $\begin{array}{l}-0.4655 \\
(0.1353)\end{array}$ & $\begin{array}{l}-0.4316 \\
(0.1098)\end{array}$ & $\begin{array}{l}-0.4506 \\
(0.0984)\end{array}$ & $\begin{array}{l}-0.1068 \\
(0.0314)\end{array}$ & $\begin{array}{l}-0.1079 \\
(0.0304)\end{array}$ & $\begin{array}{l}-0.0636 \\
(0.0199)\end{array}$ & $\begin{array}{l}-0.0673 \\
(0.0175)\end{array}$ \\
\hline U.S. undergrad & $\begin{array}{c}0.3024 \\
(0.1271)\end{array}$ & $\begin{array}{c}0.1862 \\
(0.0992)\end{array}$ & $\begin{array}{c}0.1287 \\
(0.0975)\end{array}$ & $\begin{array}{c}0.0400 \\
(0.0283)\end{array}$ & $\begin{array}{c}0.0346 \\
(0.0301)\end{array}$ & $\begin{array}{c}0.0464 \\
(0.0180)\end{array}$ & $\begin{array}{c}0.0350 \\
(0.0173)\end{array}$ \\
\hline Grad School A & $\begin{array}{c}0.6080 \\
(0.1869)\end{array}$ & $\begin{array}{c}0.4390 \\
(0.1470)\end{array}$ & $\begin{array}{c}0.2229 \\
(0.1827)\end{array}$ & $\begin{array}{c}0.1336 \\
(0.0420)\end{array}$ & $\begin{array}{c}0.1237 \\
(0.0565)\end{array}$ & $\begin{array}{c}0.1005 \\
(0.0267)\end{array}$ & $\begin{array}{c}0.0603 \\
(0.0324)\end{array}$ \\
\hline Grad School B & $\begin{array}{l}-0.6711 \\
(0.2703)\end{array}$ & $\begin{array}{l}-0.5762 \\
(0.2059)\end{array}$ & $\begin{array}{l}-0.1657 \\
(0.3106)\end{array}$ & $\begin{array}{l}-0.1322 \\
(0.0588)\end{array}$ & $\begin{array}{l}-0.1092 \\
(0.0960)\end{array}$ & $\begin{array}{c}-0.1173 \\
(0.0374)\end{array}$ & $\begin{array}{l}-0.0387 \\
(0.0551)\end{array}$ \\
\hline NSF & $\begin{array}{c}0.1936 \\
(0.0965)\end{array}$ & $\begin{array}{c}0.1881 \\
(0.0763)\end{array}$ & $\begin{array}{c}0.1019 \\
(0.0802)\end{array}$ & $\begin{array}{c}0.0455 \\
(0.0218)\end{array}$ & $\begin{array}{c}0.0406 \\
(0.0248)\end{array}$ & $\begin{array}{c}0.0352 \\
(0.0139)\end{array}$ & $\begin{array}{c}0.0194 \\
(0.0142)\end{array}$ \\
\hline Sloan & $\begin{array}{c}0.6645 \\
(0.1765)\end{array}$ & $\begin{array}{c}0.5619 \\
(0.1410)\end{array}$ & $\begin{array}{c}0.0341 \\
(0.3158)\end{array}$ & $\begin{array}{c}0.2544 \\
(0.0403)\end{array}$ & $\begin{array}{c}0.2252 \\
(0.0976)\end{array}$ & $\begin{array}{c}0.1370 \\
(0.0260)\end{array}$ & $\begin{array}{c}0.0387 \\
(0.0560)\end{array}$ \\
\hline Initial Job Rank & & & $\begin{array}{c}0.4850 \\
(0.2783)\end{array}$ & & $\begin{array}{c}0.0262 \\
(0.0860)\end{array}$ & & $\begin{array}{c}0.0900 \\
(0.0493)\end{array}$ \\
\hline $\begin{array}{l}\text { Observations } \\
R^{2} \text { (or pseudo } R^{2} \text { ) }\end{array}$ & $\begin{array}{c}1,149 \\
0.0333\end{array}$ & $\begin{array}{l}1,149 \\
0.1082\end{array}$ & 1,149 & $\begin{array}{c}1,149 \\
0.1163\end{array}$ & 1,149 & $\begin{array}{c}1,149 \\
0.1341\end{array}$ & 1,149 \\
\hline
\end{tabular}

Table 3: Publication Productivity. An observation is a person ten years after her last appearance in a CV book. See text for definitions of dependent variables. Column (1) displays the coefficients from an ordered logit. Columns (2), (4), and (6) are based on OLS regressions. Columns (3), (5), and (7) are based on IV regressions where the number of academic listings in Job Openings for Economists in the year the person last appears in a CV book is used to instrument for Initial Job Rank. The sample is limited to people who appear in two or fewer CV books. All the displayed explanatory variables are indicator variables except initial job rank. "Grad School A" is an indicator for graduating from the highest ranked of the seven graduate institutions. "Grad School B" is an indicatory for graduating from the lowest ranked institution. Each regression also has a full set of indicator variables for year on job market and graduate institutions. Standard errors are in parentheses. 
graduates in a more favorable economic climate and gets a job at a school ranked 40th. She would now be expected to create research with impact that would place her in the 69th percentile for an economist with ten years of experience. While it is hard to say what a "large" effect would be, this suggests that the type of job a person gets has an important effect on her research productivity.

I reran the IV specifications using a set of graduating year indicator variables to instrument for initial job rank. As mentioned above, the validity of this instrument requires stronger assumptions but allows me to estimate the first stage regression more flexibly. The coefficients on "initial job rank" are similar but more precise using this instrument. They are positive and significant at the $6 \%$ (column (3)), 17\% (column (5)), and 5\% (column (7)) levels.

\subsection{Second Period Placement}

I now consider the matching of economists to jobs at the beginning of career period 2. I run ordered logits to estimate factors associated with $s_{i 2}$, though I will be cautious in claiming "effects" given that I will include some endogenous explanatory variables. Nevertheless, the results here, and comparisons with estimates of factors driving first period placement, will allow me to draw some conclusions about how standards develop over economists' careers and how employers learn about economists' ability over their careers.

The results are in Table 4. Column (1) repeats the initial placement ordered logit in column (4) of Table 2 for comparison purposes. Column (2) repeats the exact same analysis on the exact same sample ten years later. Nothing changes from column (1) to column (2) except for the value of the dependent variable for any economist that changes sectors in the ten years after initial placement.

Note first that the results in the two columns look remarkably similar. Gender and undergraduate country are still insignificant. The highest and lowest ranked graduate schools have similar effects on placement. The coefficients are somewhat reduced (in absolute value), but this is to be expected given that the distribution of the dependent variable is tighter in the column (2) sample (see Table 1.) The fellowship effects are also similar across the two time frames.

There is some evidence of learning in that the goodness-of-fit for the regression (the pseudo- $R^{2}$ of the ordered logit) is smaller in column (2). This is consistent with the notion that employers are getting more accurate readings of economists' ability over this ten year period. While they had approximately the right average correlation between graduate school (for example) and initial placement, they rely less on these observed characteristics when making second period employment matches.

Columns (3) and (4) run the same specification on the same samples as columns (1) and (2), respectively, but include the person's publication record at the start of period 2 (that is, $p_{i 2}$ ) as an 


\begin{tabular}{|c|c|c|c|c|c|c|}
\hline & $\begin{array}{c}\text { Initial } \\
(1)\end{array}$ & $\begin{array}{c}10 \text { Years } \\
(2)\end{array}$ & $\begin{array}{c}\text { Initial } \\
(3)\end{array}$ & $\begin{array}{c}10 \text { Years } \\
(4)\end{array}$ & $\begin{array}{c}10 \text { Years } \\
(5)\end{array}$ & $\begin{array}{c}10 \text { Years } \\
(6)\end{array}$ \\
\hline Female & $\begin{array}{c}0.0672 \\
(0.1360)\end{array}$ & $\begin{array}{c}-0.1964 \\
(0.1406)\end{array}$ & $\begin{array}{c}0.3516 \\
(0.1402)\end{array}$ & $\begin{array}{c}0.0644 \\
(0.1424)\end{array}$ & $\begin{array}{c}-0.2154 \\
(0.1440)\end{array}$ & $\begin{array}{c}-0.0599 \\
(0.1468)\end{array}$ \\
\hline U.S. undergrad & $\begin{array}{c}0.1785 \\
(0.1239)\end{array}$ & $\begin{array}{c}0.1145 \\
(0.1243)\end{array}$ & $\begin{array}{c}0.0185 \\
(0.1260)\end{array}$ & $\begin{array}{c}-0.0733 \\
(0.1271)\end{array}$ & $\begin{array}{c}0.0408 \\
(0.1293)\end{array}$ & $\begin{array}{c}-0.0669 \\
(0.1318)\end{array}$ \\
\hline Grad School A & $\begin{array}{c}0.6554 \\
(0.1833)\end{array}$ & $\begin{array}{c}0.4995 \\
(0.1864)\end{array}$ & $\begin{array}{c}0.3058 \\
(0.1881)\end{array}$ & $\begin{array}{c}0.1122 \\
(0.1895)\end{array}$ & $\begin{array}{c}0.0860 \\
(0.1932)\end{array}$ & $\begin{array}{c}-0.0625 \\
(0.1962)\end{array}$ \\
\hline Grad School B & $\begin{array}{c}-1.294 \\
(0.2526)\end{array}$ & $\begin{array}{l}-0.8526 \\
(0.2494)\end{array}$ & $\begin{array}{c}-1.037 \\
(0.2579)\end{array}$ & $\begin{array}{l}-0.4850 \\
(0.2592)\end{array}$ & $\begin{array}{l}-0.1578 \\
(0.2628)\end{array}$ & $\begin{array}{c}-0.0763 \\
(0.2676)\end{array}$ \\
\hline $\mathrm{NSF}$ & $\begin{array}{c}0.1860 \\
(0.0962)\end{array}$ & $\begin{array}{c}0.2104 \\
(0.0986)\end{array}$ & $\begin{array}{c}0.0742 \\
(0.0966)\end{array}$ & $\begin{array}{c}0.1035 \\
(0.0968)\end{array}$ & $\begin{array}{c}0.0838 \\
(0.1001)\end{array}$ & $\begin{array}{c}0.0245 \\
(0.1010)\end{array}$ \\
\hline Sloan & $\begin{array}{c}1.390 \\
(0.1871)\end{array}$ & $\begin{array}{c}1.214 \\
(0.1823)\end{array}$ & $\begin{array}{c}1.003 \\
(0.1886)\end{array}$ & $\begin{array}{c}0.8025 \\
(0.1842)\end{array}$ & $\begin{array}{c}0.2976 \\
(0.1897)\end{array}$ & $\begin{array}{c}0.2235 \\
(0.1931)\end{array}$ \\
\hline 10-Year Impact & & & $\begin{array}{c}4.050 \\
(0.2418)\end{array}$ & $\begin{array}{c}4.901 \\
(0.2563)\end{array}$ & & $\begin{array}{c}3.099 \\
(0.2737)\end{array}$ \\
\hline Initial Job Rank & & & & & $\begin{array}{c}1.307 \\
(0.0571)\end{array}$ & $\begin{array}{c}1.080 \\
(0.0600)\end{array}$ \\
\hline Observations & 1,149 & 1,149 & 1,149 & 1,149 & 1,149 & 1,149 \\
\hline Pseudo $R^{2}$ & 0.0505 & 0.0379 & 0.1338 & 0.1560 & 0.2243 & 0.2621 \\
\hline
\end{tabular}

Table 4: Second-Period Placement. An observation is a person either in the year after last appearing in a CV book (columns 1 and 3) or ten years after last appearing in a CV book (other columns). The sample in all columns is limited to people available for the 10-year analyses. Each column shows the coefficients from an ordered logit. See Table 2 for details on the dependent variable and sample. 10-year impact is where the person stands in the cumulative distribution of impactweighted publications as of the time of the observation. Initial job rank is the same as the dependent variable in column 1. "Grad School A" is an indicator for graduating from the highest ranked of the seven graduate institutions. "Grad School B" is an indicator for graduating from the lowest ranked institution. Each regression also has a full set of indicator variables for year on job market and graduate institutions. Standard errors are in parentheses. 
explanatory variable. As shown above, first period placement affects productivity and, as shown in Oyer (2006a), initial placement also affects later placement. So I cannot think of the productivity variable as entirely exogenous. However, I would hope that the primary determinant of productivity is ability and that I can think of productivity as a critical means through which the market learns about the economist's ability.

Column (4) shows that first period research productivity is highly correlated with second period sector. Specifically, the 4.9 coefficient on 10-Year Impact means that an economist that is 20 percentage points higher than another economist in the impact distribution during period one will be one sector higher than the other economist in the second period job match. In other words, if one economist is at the median of the impact distribution and holds a job at a ranked institution not in the Top 50 (that is, $s_{i 2}=2$ ), then an economist that is equivalent at the seventieth percentile of the impact distribution who is otherwise equivalent to the first economist could expect to hold a Top 26-50 $\left(s_{i 2}=3\right)$ job.

As mentioned above, it would be inappropriate to interpret this relationship between second period sector and first period productivity as causal. Column (3) provides strong evidence to support this concern, because it shows that productivity in the first period is highly correlated with initial job sector. This relationship was to be expected, given the results in Table 3. Note, however, that the coefficient on 10-Year Impact is higher for the 10 Year sample (that is, the coefficient is higher in column (4) than in (3)) and remember that, other things equal, the coefficient should go down over time as the variance in the dependent variable gets smaller. Therefore, though any result with an endogenous right-hand-side variable should be interpreted cautiously, a comparison of columns (3) and (4) provides evidence that is at least consistent with employers drawing inferences about economists' ability from publication productivity (or, equivalently, that they learn about economists' ability during period 1 and ability is correlated with productivity.) The pseudo- $R^{2}$ statistics of these two specifications also suggest learning, in that there is a better fit after ten years.

Note that, when comparing columns (4) and (2), the effects of all the exogenous variables are lowered when controlling for publication productivity. This result (though complicated by the endogeneity issue) and the comparison between columns (1) and (2) are similar to the results in Farber and Gibbons (1996) and Altonji and Pierret (2001). The fact that the coefficients are largely unchanged from column (1) to (2), while the goodness-of-fit decreases, suggests that the market makes correct "average" guesses about ability using observable characteristics. However, over time, the market focuses more on unobserved ability measures, which lowers the explanatory power of the initially observable characteristics. Adding a measure that is correlated with unobserved ability (in 


\begin{tabular}{ccc}
\hline \hline & $\begin{array}{c}\text { Initial } \\
(1)\end{array}$ & $\begin{array}{c}\text { 10 Years } \\
(2)\end{array}$ \\
\hline$m_{1}$ & 2.247 & 2.289 \\
& $(0.3884)$ & $(0.2994)$ \\
$m_{2}$ & 1.359 & 1.594 \\
& $(0.3836)$ & $(0.3944)$ \\
$m_{3}$ & 0.9438 & 1.206 \\
& $(0.3825)$ & $(0.3929)$ \\
$m_{4}$ & -0.6629 & -0.3789 \\
& $(0.3821)$ & $(0.3909)$ \\
$m_{5}$ & -2.436 & -1.961 \\
& $(0.3923)$ & $(0.3956)$ \\
\hline
\end{tabular}

Table 5: Estimates of Sector Cut-Offs. These cut-offs correspond to the ordered logits in the first two columns of the prior table.

this case, productivity) increases overall explanatory power while lowering the effect of observable characteristics that affect outcomes only because of their use in drawing inferences about expected ability. Farber and Gibbons (1996) and Altonji and Pierret (2001) draw these inferences by looking at how pay progresses over workers' careers, rather than how job sector develops.

Columns (5) and (6) run two more ordered logit specifications on second-period sector assignment. They add a variable (initial job sector) that has the downside of further complicating endogeneity issues but the advantage of providing a measure of the market's estimate of the economist's ability at the start of the first career period. In both regressions, the coefficient is one or above, suggesting that a better first job will, in expectation, be associated with a better job later on. ${ }^{15}$ Interpreting initial job rank as a measure of initial market expectations about ability, it is no great surprise that no other observable characteristics known at the time of initial job search have a significant correlation with second period job sector. However, even controlling for first-period sector, first-period productivity is related to second-period sector. This suggests that the market learns about the economist early in her career and uses this learning to assign her in the second period.

Table 5 provides further details on the ordered logits in columns (1) and (2) of Table 4 . The ordered logit estimates the cut-offs for each sector corresponding to the $m$ 's in equations (4) and (6). Because the first two columns of Table 4 use exactly the same sample and explanatory variables, the estimated $m$ 's can be compared to determine if standards change over a person's career. If

\footnotetext{
${ }^{15}$ In Oyer (2006a), I estimate that 50-80\% of random improvements in initial job placement will be permanent. That is, getting an initial job that is one unit better along some dimension will lead to a job that is $0.5-0.8$ units better in period 2 .
} 
the cutoffs get higher over time, this indicates that standards to get into a given job sector rise over time. That is, $m$ 's that are higher in column (2) than in column (1) indicate that, everything else equal, a person can expect to move to a less prestigious job in the first ten years after initial placement. In all five cases, the estimated cutoffs do increase. Though they are not individually significantly different, all the cutoffs suggest that the cutoffs get more demanding over time. In an unreported ordered logit, I combined all the observations in both specifications in Table 5 and included an indicator for an observation at the tenth year. This coefficient was positive and significant, implying that the joint test that each pair of coefficients in Table 5 is equivalent can be rejected.

\subsection{Are Initial Placements Rational?}

Though some of the analysis to this point has already touched on this, I now look for evidence that initial placements systematically misallocate economists of some observable type. For example, if women or graduates of School B are, on average, undervalued when they graduate, the analysis in this section will hopefully find some evidence of this.

The way I will approach this question is to look at how changes in types of jobs are related to individual characteristics. That is, I will combine equations (4) and (6) and then use logits or OLS to estimate

$$
f\left(s_{i 2}, s_{i 1}\right)=h+k x_{i 1 t}+\varphi_{i}
$$

where $f$ is some function of the change in sector (or a more-detailed measure of job rank) between initial placement and second-period placement. The three variations on the $f$ function that I will use are an indicator for whether the person moved to a lower ranked sector (that is, $f\left(s_{i 2}, s_{i 1}\right)=$ $\left.I\left(s_{i 2}<s_{i 1}\right)\right)$, the change in sector $\left(s_{i 2}-s_{i 1}\right)$, and the change in the econphd.net ranking of the institution where the person works.

This approach will uncover systematic, but "honest", mistakes. If, for example, women are discriminated against at both the initial and later phases, then this will not lead to women being any more likely than men to change sectors. But if each employer wants the highest ability person for any position and the market systematically underestimates women's early career productivity, then women will be more likely than men to move to more prestigious jobs.

Table 6 displays the results. Column (1) shows the results when the full sample is used and the dependent variable is an indicator for whether or not the person moves to a "worse" sector. This creates problems, because the people with initial placement in higher-ranked sectors have to 


\begin{tabular}{|c|c|c|c|c|c|}
\hline $\begin{array}{l}\text { Dependent Variable } \\
\text { Sample }\end{array}$ & $\begin{array}{c}\text { Sector Drop } \\
\text { All } \\
(1)\end{array}$ & $\begin{array}{c}\text { Sector Drop } \\
s_{i t}=5 \\
(2)\end{array}$ & $\begin{array}{c}\text { Sector Drop } \\
s_{i t} \in[3,5] \\
(3)\end{array}$ & $\begin{array}{c}\Delta \text { Sector } \\
s_{i t} \in[2,4] \\
\quad(4)\end{array}$ & $\begin{array}{c}\Delta \operatorname{Rank} \\
50<\operatorname{rank}<150 \\
(5)\end{array}$ \\
\hline Female & $\begin{array}{c}0.0385 \\
(0.0338)\end{array}$ & $\begin{array}{l}-0.1989 \\
(0.1212)\end{array}$ & $\begin{array}{l}-0.0417 \\
(0.0669)\end{array}$ & $\begin{array}{l}-0.2565 \\
(0.1139)\end{array}$ & $\begin{array}{c}17.29 \\
(26.84)\end{array}$ \\
\hline U.S. undergrad & $\begin{array}{c}0.0116 \\
(0.0314)\end{array}$ & $\begin{array}{l}-0.0435 \\
(0.1203)\end{array}$ & $\begin{array}{l}-0.0295 \\
(0.0668)\end{array}$ & $\begin{array}{l}-0.0657 \\
(0.1045)\end{array}$ & $\begin{array}{c}26.87 \\
(23.11)\end{array}$ \\
\hline Grad School A & $\begin{array}{c}0.0189 \\
(0.0459)\end{array}$ & $\begin{array}{c}0.0011 \\
(0.1485)\end{array}$ & $\begin{array}{l}-0.0890 \\
(0.0899)\end{array}$ & $\begin{array}{c}0.0239 \\
(0.1472)\end{array}$ & $\begin{array}{c}-3.54 \\
(32.58)\end{array}$ \\
\hline Grad School B & $\begin{array}{l}-0.1695 \\
(0.0755)\end{array}$ & $\mathrm{N} / \mathrm{A}$ & $\begin{array}{l}-0.0485 \\
(0.2187)\end{array}$ & $\begin{array}{l}-0.3678 \\
(0.3222)\end{array}$ & $\begin{array}{l}160.16 \\
(96.93)\end{array}$ \\
\hline NSF & $\begin{array}{l}-0.0097 \\
(0.0237)\end{array}$ & $\begin{array}{l}-0.0914 \\
(0.0646)\end{array}$ & $\begin{array}{l}-0.0327 \\
(0.0397)\end{array}$ & $\begin{array}{l}-0.0438 \\
(0.0776)\end{array}$ & $\begin{array}{c}-7.91 \\
(19.58)\end{array}$ \\
\hline Sloan & $\begin{array}{c}0.0025 \\
(0.0432)\end{array}$ & $\begin{array}{l}-0.1323 \\
(0.1039)\end{array}$ & $\begin{array}{l}-0.0706 \\
(0.0703)\end{array}$ & $\begin{array}{c}0.0527 \\
(0.1594)\end{array}$ & $\begin{array}{l}-39.79 \\
(33.86)\end{array}$ \\
\hline Academic $J O E$ & $\begin{array}{c}0.3127 \\
(0.1794)\end{array}$ & $\begin{array}{c}1.0602 \\
(0.6433)\end{array}$ & $\begin{array}{c}0.5480 \\
(0.3712)\end{array}$ & $\begin{array}{l}-1.5056 \\
(0.6121)\end{array}$ & $\begin{array}{c}-39.02 \\
(140.15)\end{array}$ \\
\hline $\begin{array}{l}\text { Observations } \\
\text { Pseudo } R^{2}\end{array}$ & $\begin{array}{c}1,149 \\
0.0162\end{array}$ & $\begin{array}{c}151 \\
0.1133\end{array}$ & $\begin{array}{c}376 \\
0.0462\end{array}$ & $\begin{array}{c}618 \\
0.0355\end{array}$ & $\begin{array}{c}171 \\
0.0580\end{array}$ \\
\hline
\end{tabular}

Table 6: Change in Job Quality. "Sector" $\left(s_{i t}\right)$ is defined in prior tables and in the text. Columns 1-3 show marginal coefficients from logits where the dependent variable is an indicator variable that equals one if the person's sector ten years after leaving school is lower ranked than her sector right after leaving school. Column 4 shows the results of an OLS regression where the dependent variable is the sector ten years after leaving school minus the sector right after leaving school. Column 5 shows the results of an OLS regression where the dependent variable is the econphd.net rank of the person's institution ten years after leaving school minus the rank of her institution right after leaving school.

be more likely to drop sectors than those who sort to lower sectors. Not surprisingly, I find School B graduates are less likely to drop sectors, but this may be because they have fewer opportunities to drop sectors. The only other remotely significant coefficient is on the "Academic JOE" variable that was used as an instrument in the productivity regressions. The coefficient indicates that economists who left school in a year with $10 \%$ more JOE listings than another year will have $3 \%$ higher probability of dropping sectors than graduates from the comparison year. This is relative to an unconditional probability of $30 \%$ and is statistically significant at the $9 \%$ level.

The positive coefficient on the macroeconomic variable is somewhat expected in column (1) given that graduates in good years place better and, therefore, have more opportunity to fall. However, in all specifications, the sign on this variable indicates that graduates in good economic 
times are more likely to fall to less prestigious positions in their first ten years. The effect is significant at the $10 \%$ level in column (2) and at the $2 \%$ level in column (4). In column 4, the 1.51 coefficient suggests that a $10 \%$ increase in $J O E$ listings is associated with an expected move down of 0.15 sectors over the first ten years after a cohort leaves school.

Column 2 analyzes the 151 people who obtain initial sector 5 (that is, tenure-track Top 10) positions. While this is a small sample, $46 \%$ of them drop so there is a fair amount of variation. The female coefficient, which is significant at the $10.1 \%$ confidence level, indicates that women who obtain Top 10 positions are much more likely to keep them than men. Unfortunately, this variable, even if it can be considered statistically significant, is particularly hard to interpret. It could indicate the very different possibilities that women are discriminated against in initial hiring (though the results in Tables 2 and 4 do not imply this) or that they are given affirmative action at the promotion and tenure phase. Alternatively, it could just be that many women stop or slow down their tenure clocks and they are less likely to have actually matched to their final sector after ten years. In any case, this effect is reversed in column 4, which suggests, relative to men, women who start in sectors 2-4 (that is, tenure track jobs at ranked institutions outside the Top 10) are likely to move to less prestigious sectors. Together, these results are consistent with women being somewhat favored at the very top institutions and men being favored at other research institutions. But making any firm conclusion along these lines would require further analysis.

Besides the female and $J O E$ variables, there are no significant or consistent results in the table. The general lack of significance of the graduate school effects suggests that employers of economists do not systematically overestimate or underestimate the ability of graduates of particular schools. However, Smeets et al. (2006) argue that second-tier graduates of top-tier graduate programs are systematically underplaced and end up moving "up" relative to top graduates of second-tier programs. The fact that this pattern does not show up in Table 6 could be due to any of several factors. For example, the school-level variables may not pick up differences among subgroups of graduates from a particular program. Also, Smeets et al. (2006) focus on graduates from many schools in a short sample period while I use graduates of fewer schools over a longer horizon. If hiring institutions improved their practices, the patterns Smeets et al. (2006) uncover may not hold over the longer period. An alternative explanation is that Smeets et al. (2006) draw different conclusions because they use different sector and rank variables than I do.

Yet another possible reconciliation of the results here with those in Smeets et al. (2006) could be due to differences in "option value" when people graduate from $\mathrm{PhD}$ programs. If the top students at each school are also the ones with the greatest variance in their performance, then schools will find them relatively attractive given they can deny tenure to those that turn out to 
be less productive. This would explain why top students at second-tier schools are on average less productive and successful than second-tier students at top schools, but more sought after in the initial job market. But, if this is true for top students at all schools or for only a very small fraction of students overall, there would be no significant differences by schools in how often their graduates move "up" or "down" in job quality. Note that I found no correlation between variation in research productivity and any characteristics that are observable in the dataset, though variability at the time of leaving school could well vary in ways that hiring institutions can observe.

Overall, I interpret the results in Table 6 as providing suggestive evidence on three issues. First, there are some curious differences in the patterns of movements of male and female economists early in their career that merit further (and more careful) analysis. Second, there is some evidence that, when demand for economists is strong, employers hire either more economists (or lower-quality economists) than they will need in steady state. These economists are more likely to move to lower ranked employers in the first ten years after leaving school. Third, there is no evidence to suggest that the market systematically mis-values graduates of specific schools, NSF and Sloan fellowships, or an economist's country of origin. These conclusions are subject to the important qualifications noted at the beginning of this section.

The second conclusion, which suggests that economists get "over-placed" in favorable macroeconomic markets, suggests that universities could benefit by hiring counter-cyclically. That is, a single institution might be able to get higher ability economists if it hired when others do not. This would be a difficult strategy to follow, as it would be hard to commit the institution to not hire when resources are readily available. One potentially fruitful avenue for future research would be to estimate the value of this hiring strategy for different types of institutions that hire economists.

\section{Conclusions and Future Research}

In this paper, I have used careers of economists to confirm several intuitively appealing ideas about careers of high-skill workers. First, I showed that worker productivity and human-capital development is affected by the type of jobs they hold. Second, I showed evidence that suggests employers learn about employees' ability early in their careers and that this is related to where those employees work as their careers develop. I also showed that, though employers do not make perfect predictions about new graduates' ability, there is no evidence that they make systematic mistakes. They appear to appropriately value, for example, the signal of graduating from the most prestigious graduate school.

There are at least four potentially fruitful avenues for future research based on the analysis 
here. First, either through a survey or some other data source, collecting information on wages could yield further insights into the economist labor market. Second, I have had to qualify the implications of this analysis due to the difficulty in separately identifying how productivity and job placement are determined (and how they determine one another.) Structural modeling of the underlying processes or identification of credible instruments for endogenous variables would lead to sharper conclusions about causality in the career development process and to a more complete understanding of the underlying labor market.

Third, while I have shown that the average economist moves "down" in the first ten years of her career, I have said nothing about why this is the case. But this appears to be a broader empirical regularity across professional labor markets, with lots of graduates of top schools starting at high profile employers (such as top law firms, top consulting firms, leading technology companies, etc.) For example, consider Figure 3. It shows the cumulative distribution of job market entry (defined, somewhat less exactly than in the rest of this paper, as date received highest degree) of employees at three types of institutions. The solid line is based on the departments of economics at three leading research universities. The line that closely tracks the solid line is based on departments of economics at universities where economists engage in research but where the department ranks forty-second or lower. The dotted line is the distribution for a single large law firm (which appears to be representative of large law firms.) The figure suggests three slightly different experience profiles within each of these three types of organizations. At the non-leading economics departments, the distribution is nearly uniform. Among junior economists, some move down to lower ranked schools and get replaced by people who drop down from top-ranked schools. At top schools, the distribution is weighted a little more towards junior economists, many of whom will move down to lower-ranked institutions for the bulk of their careers. But this law firm, which has an "up-or-out" system similar to a university tenure system, is weighted even more heavily towards junior employees. For every lawyer with twenty to twenty-five years of experience, there are about four with under five years of experience. Why do law firms use such high leverage relative to economics departments? Is the value of employer learning higher? Is the value of early career human capital development higher (and more concentrated)? Is there a specific reason to sample some types of jobs early in one's career (as suggested by Miller (1984) and MacDonald (1982))? Future research could model and measure these environments to shed light on optimal organizational design at high-skill employers.

Finally, Section 4.4 presented evidence that suggests universities and other employers of economists can improve the average ability of their new hires if they hire counter-cyclically. That is, competition for economist skill varies with macroeconomic trends. If a university hires when demand is low, it will find higher ability economists available. Why don't employers (or, to the extent 


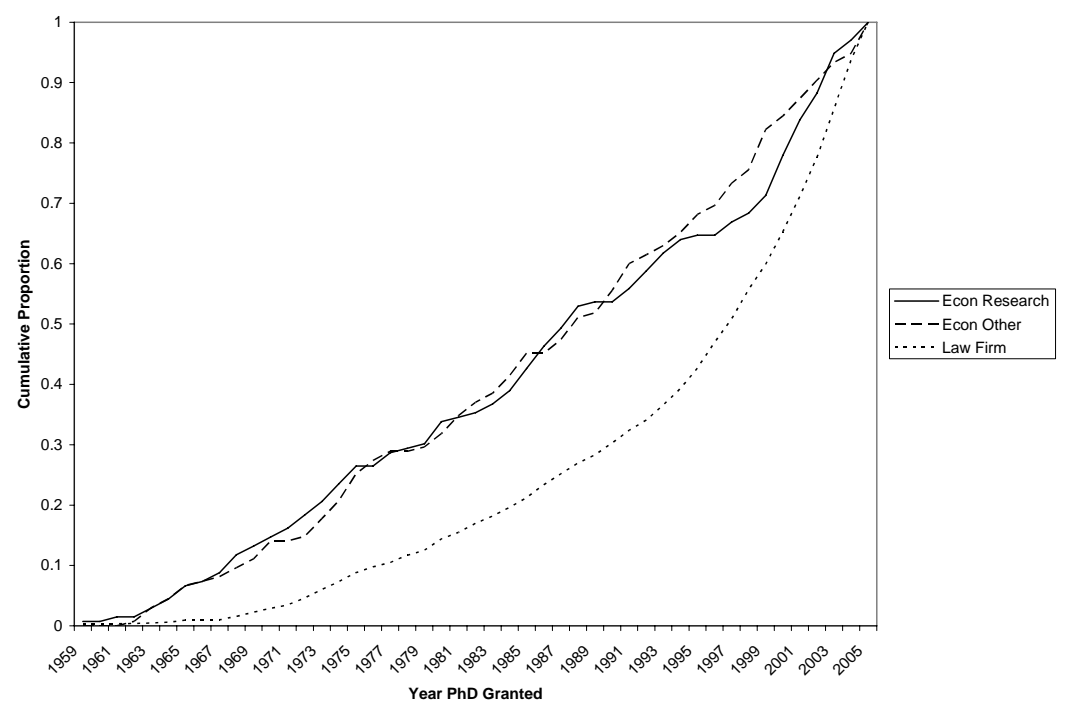

Figure 3: Distribution of Labor Market Entry Dates. "Econ Research" includes the departments of economics at Harvard, MIT, and Princeton in 2005-2006. "Econ Other" includes the departments of economics at Rice, George Washington, Tulane, Emory, St. Louis, Middlebury, and Boston College. "Law Firm" is based on lawyer profiles on the website of one of the world's five largest law firms, as of January, 2006.

that some already do it, more employers) employ this hiring strategy? One constraint may be the difficulty of committing to not hiring when resources are available. Future research could, after measuring or making assumptions about the value of increased research productivity, estimate the cost of this inability to commit to a counter-cyclical strategy. 


\section{References}

Altonji, Joseph G. and Charles R. Pierret, "Employer Learning and Statistical Discrimination," Quarterly Journal of Economics, 2001, 116, 313-350.

Carmichael, H. Lorne, "Incentives in Academics: Why is There Tenure?," Journal of Political Economy, 1988, 96, 453-472.

Chen, Yonmin and Terra McKinnish, "Do Economics Departments Search Optimally in Faculty Recruiting?," Economic Inquiry, 2005, 43, 676-688.

Farber, Henry S., "Mobility and Stability: The Dynamics of Job Change in Labor Markets," in Orley Ashenfelter and David Card, eds., Handbook of Labor Economics, Volume 3, New York: North-Holland, 1999.

__ and Robert Gibbons, "Learning and Wage Dynamics," Quarterly Journal of Economics, 1996, 111, 1007-1047.

Gibbons, Robert, Lawrence F. Katz, Thomas Lemieux, and Daniel Parent, "Comparative Advantage, Learning, and Sectoral Wage Determination," Journal of Labor Economics, 2005, 23, 681-723.

Jovanovic, Boyan, "Job Matching and the Theory of Turnover," Journal of Political Economy, 1979, 87, 972-990.

Kahn, Charles and Gur Huberman, "Two-sided Uncertainty and ŚUp-or-OutŠ Contracts," Journal of Labor Economics, 1988, 6, 423-444.

Lazear, Edward P., "Hiring Risky Workers," in Isao Ohashi and Toshiaki Tachibanaki, eds., Internal Labour Markets, Incentives, and Employment, New York: St. MartinŠs Press, 1998.

MacDonald, Glenn M., "A Market Equilibrium Theory of Job Assignment and Sequential Accumulation of Information," American Economic Review, 1982, 72, 1038-1055.

Miller, Robert A., "Job Matching and Occupational Choice," Journal of Political Economy, 1984, 92, $1086-1120$.

Oyer, Paul, "Initial Labor Market Conditions and Long-Term Outcomes for Economists," Journal of Economic Perspectives, 2006, 20, 143-160.

_ - "The Making of an Investment Banker: Macroeconomic Shocks, Career Choice, and Lifetime Income," Working Paper 12059, National Bureau of Economic Research 2006.

Smeets, Valerie, Frederic Warzynski, and Tom Coupe, "Does the Academic Labor Market Initially Allocate New Graduates Efficiently?," Journal of Economic Perspectives, 2006, 20, 161-172. 